\title{
Impacto da Manufatura Aditiva nos Processos Tradicionais de Produção: Um Estudo de Caso em Joalheria Artesanal
}

Impact of Additive Manufacturing on Traditional Production Processes: A Case Study in Artisanal Jewelry

\section{Resumo}

Atualmente, com as novas formas de produzir, em que as organizações buscam gastar menos e produzir mais as tecnologias ganham espaço para apoiar essas novas formas de produção. 0 uso da impressão 3D vem quebrando paradigmas e criando valor para os clientes de uma forma a transformar as maneiras tradicionais de produção. No setor joalheiro essa tecnologia já vem sendo utilizada como ferramenta de construção de modelos, um trabalho anteriormente realizado manualmente por um modelador. Nesse artigo os processos de fabricação de joias tradicionais serão apresentados e também será abordada a utilização da tecnologia de prototipagem por impressão 3d no setor joalheiro. Além de um estudo de caso comparando a fabricação de uma joia pelo modo tradicional e com o uso da manufatura aditiva. Foi comparado o processo de desenvolvimento de um projeto de uma joia, através do processo de manufatura artesanal tradicional, onde o desenho do artesão foi modelado em software CAD e submetido a uma plataforma online de serviços de impressão em ouro, para efeitos de comparação. Evidenciamos o potencial de aplicação desta tecnologia emergente e a possibilidade da otimização e redução de custos. Em contraposição, também realçamos a importância fundamental da produção artesanal e o valor atribuído a esta atividade neste setor produtivo específico.

\section{Abstract}

Nowadays, with new forms of production, where organizations seek to spend less and produce more technologies, they gain space to support these new forms of production. The use of 3D printing has been breaking paradigms and creating value for customers in a way that has transformed traditional ways of production. In the jeweler sector, this technology has already been used as a model building tool, a work previously done manually by a modeler. In this article the traditional jewelry manufacturing processes will be presented and the use of $3 d$ printing prototyping technology in the jeweler industry will also be addressed. In addition to a case study comparing the manufacture of a jewel by the traditional way and with the use of the additive manufacture. The development process of a jewelry project was compared through the traditional artisan manufacturing process, where the artisan design was modeled in a CAD software and submitted to an online gold printing services platform for comparison purposes. We show the potential of applying this emerging technology and the possibility of optimization and cost reduction. In contrast, we also emphasize the fundamental importance of artisanal production and the value attributed to this activity in this specific productive sector 


\section{INTRODUÇÃO}

Até o século XIX a produção artesanal e de pouca concorrência era predominante, isso muda com a Revolução Industrial onde se passa a utilizar máquinas em larga escala. Dando a produção de bens de consumo um ritmo mais acelerado onde se produz em massa, o trabalho passa a ser dividido e a ideia de padronização das tarefas e produtos é criada. Após a Segunda Guerra Mundial as organizações japonesas ganham espaço no mercado e pautam sua produção na qualidade de seus produtos. Com o aumento de competitividade no mercado e capacidade tecnológica, a capacidade produtiva também aumenta, assim as formas de produzir vem evoluindo a cada dia.

Em uma realidade onde as empresas buscam entregar produtos em menor tempo, com menores custos, primando pela confiabilidade e eficiência para se manterem competitivos no mercado, enxergamos as tecnologias, cada vez mais, auxiliando e criando novas formas de produzir que trazem grandes benefícios tanto para os consumidores quanto para os produtores.

Nesse contexto, a Manufatura Aditiva, impressão 3D, vem ganhado espaço se mostrando presente em vários segmentos do mercado, como por exemplo iluminação, calçados, próteses, instrumentos musicais, automotivo, aeronáutica e joalheria. Esta última já consegue aplicar essa tecnologia de forma consistente e regular em parte de seu processo de fabricação.

Neste trabalho, desenvolvemos um estudo de caso em que será avaliado o uso da impressão 3D para produção de joias comparado ao processo artesanal tradicional de confecção de produtos desse setor. Como metodologia, desenvolvemos uma breve pesquisa bibliográfica de forma exploratória e a condução do estudo de caso proposto, com o objetivo de analisar o impacto dessa tecnologia mostrar como a impressão 3D tem mudado o processo produtivo no ramo joalheiro e como essa mudança vem de encontro com as tendências de produção atuais baseadas em diminuição de desperdício, custo e tempo.

A joia que será tema desse estudo de caso teve o design e confecção feita pelo artesão/ourives Doug Andrews, um ourives por formação pela Golden West Trade School em Vernon, British Columbia no Canadá. Doug se formou em 1988 e fundou sua joalheria, Karateristics, em 1995, da qual é dono e ourives até hoje. O estudo não abordará todas as etapas de fabricação do anel, a análise será feita até a fase que antecede o acabamento. Na produção artesanal serão analisadas seguintes fases: design da peça, modelagem em cera e processo de fundição por cera perdida. No processo por impressão 3D as fases serão: modelagem em software, simulação da impressão da peça no site Shapeways. 


\section{AS VANTAGENS DA APLICAÇÃO DA TECNOLOGIA DA IM- PRESSÃO 3D}

Desenvolvida na década de 80 a impressão 3D é uma tecnologia que permite a criação de objetos físicos a partir de um modelo digital. Com o uso de um software de edição em três dimensões faz-se o modelo do objeto que se deseja imprimir, envia o arquivo do modelo para o software da impressora, configura-se as características principais do objeto, como suas dimensões, a espessura das camadas sobrepostas. Após todas as configurações a impressora compila essas informações e divide o modelo digital em diversas camadas, "fatias", e então o processo de imprimir a peça se inicia. De acordo com Lipson e Kurman (2013) impressoras 3D fazem coisas seguindo instruções de um computador, acumulando em camadas materiais crus. Existem várias técnicas de impressão 3D, mas as três técnicas mais usadas atualmente são a Estereolitografia (SLA), a Sintetização Seletiva a Laser (SSL) e a Modelagem por Fusão e Deposição (FDM). (GREENBERG, 2014; LIPSON; KURMAN, 2013).

Lipson e Kurman (2013) descreveram ainda como a impressão 3D ajudou a vencer barreiras de custos, tempo e complexidade, com princípios são baseados na liberdade na complexidade da manufatura e na variedade. Ou seja, a complexidade da peça não impacta no seu custo e, diferente da manufatura tradicional, a manufatura aditiva pode fazer vários objetos diferentes sem custos de treinar pessoas, ou comprar novas ferramentas. Apenas necessita de um novo modelo digital e novo matéria cru para imprimir. Além disso, a montagem não é mais necessária, pois a impressora 3D pode fabricar conjuntos de peças já montados. Os autores citam ainda o lead time (tempo de espera) igual a zero, onde a impressão 3D permite uma entrega imediata, imprimindo sobre demanda e próximo ao cliente. O espaço para investidas em design se torna, portanto, ilimitado. Ao contrário da forma tradicional de manufatura não se tem limitação de formas com a impressão $3 \mathrm{D}$, que determina uma liberdade para se projetar com pouca ou quase nenhuma limitação técnica. Estes autores citam ainda a baixa necessidade de espaço (manufatura compacta), a baixa necessidade de treinamento, o baixo nível de desperdício em relação às técnicas subtrativas de manufatura, além das infinitas possibilidades de misturas de materiais (compósitos, inclusive) e, principalmente, da possibilidade de se obter réplicas perfeitas de um mesmo objeto.

Além dessas vantagens - por se tratar de uma ferramenta que se utiliza de um design de base digital, que serve de base para que o objeto comece a ser fabricado - se comparado as técnicas de prototipagem tradicionais, onde o modelo muitas vezes é feito de forma artesanal, se alterações forem exigidas, essas podem ser feitas em menos tempo e de maneira mais exata e enxuta (ABREU, 2015; GREENBERG, 2014; LIPSON; KURMAN, 2013). 


\section{A JOALHERIA ARTESANAL TRADICIONAL}

As joias são utilizadas desde a pré-história, onde essas eram de ossos, pedras, dentes, conchas, madeira. Naquela época o papel da joia era ressaltar o status e papel dos indivíduos na sociedade, e serviam de amuletos protetores. Com o passar do tempo cada povo, romanos, egípcios, gregos, dentre outros, passaram a desenvolver joias em metais das mais variadas formas e o uso de joias foi mudando de propósito. Segundo Hohkraut (2010), a joia tem principal função de decoração, onde o mais importante é seu ponto de vista estético o que a tornar visualmente atrativa. Devido a mudanças na forma e motivo de uso de joias surgiu uma segmentação variada nesse setor.

Em 1960, segundo Copruchinski (2011) a joalheira se divide em duas tendências, joalheria tradicional que valoriza os materiais usados na fabricação da joia, e a joalheria artística em que o artista cria como forma de expressão sem que o material, ou a moda sejam relevantes assim como na primeira tendência. E como Gola (2008) relata a joalheria se separa em artesanal e industrial, onde a artesanal produz lotes reduzidos e exclusivos, por artesões que dominam técnicas de fabricação de joias. E a joalheria industrial visa o aspecto comercial com foco na produção em série, utiliza maquinários especifico para ganho de produtividade.

A exigência do mercado por cada vez mais produtos de maior qualidade, a gestão do sistema de produção passa a ser fundamental, então controlar os processos de produção torna-se um passo importante na fabricação de produtos (SLACK, 2009). E o modo de produção é importante no desenvolvimento dos objetos, pois, segundo Paim (2009), deve-se levar em consideração como os objetos são feitos e como a sua realização, enquanto processo consciente, produz sentido, seja o objeto industrial ou artesanal.

A produção de joias de forma artesanal se dá por processos estritamente manuais, onde um ourives executa desde o design da peça, até o produto acabado para entrega ao cliente. Nesse processo o artesão, utiliza de seus conhecimentos tácitos e suas habilidades com os materiais para criar e desenvolver suas peças. A fundição de metais e ligas são práticas diárias do ourives e da indústria joalheira. Esses metais e ligas após a fusão, serão devidamente separado da escoria e vertidos em lingoteiras para adquirirem a forma que facilitará o manuseio do metal, os lingotes. Após o metal já ter se solidificado, esses lingotes passam por diversos processos de transformação como conformação, solda, corte, cravação e tratamentos térmicos para que o material adquira a forma e características desejada pelo artesão (KLIAUGA; FERRANTE, 2009).

O processo de conformação trata de modificar o formato do material através de esforços mecânicos, aquecendo ou não o material. Esses processos podem ser o forjamento, a laminação, o corte e a trefilação. Para os processos de união, geralmente é empregada a técnica de soldagem. A cravação é a técnica utilizada para prender pedras às joias, normalmente é o último processo a ser realizado antes 
do polimento da joia, e requer ferramental próprio para a execução desse processo. Os processos de produção industrial de joias em escala são diversos, para cada um dos processos artesanais descritos existe uma adaptação para a produção em massa em que uma parte do trabalho manual é substituído por processos mecanizados com aplicação de moldes, gabaritos e matrizes (COPRUCHINSKI, 2011; KLIAUGA; FERRANTE, 2009; GOLA, 2008; SIAS, 2005).

O processo de fundição por cera perdida, uma das mais antigas técnicas utilizadas, é a mais utilizada para fabricação de joias em escala, segundo Sias (2005) existem evidências de utilização desse processo a 4200 anos antes de cristo.

Segundo Sias (2005), essa técnica parte de um modelo piloto, normalmente em metal ou cera, feitos artesanalmente. Em produções artesanais de peças unitárias, em pequenas ourivesarias, modela-se direto na cera, e cria-se o molde em massa refratária direto desse modelo. Para a produção em massa utiliza-se o piloto em metal que será embutido em camadas de borracha. A borracha será vulcanizada criando-se o molde, que será cortado para a retirada do modelo metálico, deixando a cavidade que será preenchida por cera. Esse mesmo corte servirá para obter os modelos em cera que poderão ser reproduzidos inúmeras vezes. Agrupando esses modelos em uma haste de cera forma-se a árvores de fundição. Após a árvore de fundição criada, a colocamos em um cilindro de aço, em que é vazada a massa de revestimento cerâmico. Após a secagem da massa refratária, o cilindro é aquecido para a remoção da cera (Figura 1).

Figura 1 - Etapas da fundição por cera perdida.



Fonte: Kliauga e Ferrante, 2009, p. 188. 
O conjunto, cilindro e massa refratária, são levados ao forno para a etapa de calcinação, etapa essa que consiste no tratamento térmico aplicado para a remoção da água presente na massa alterando sua estrutura tornando o material sólido. Após essa etapa vaza-se o metal líquido na árvore que foi formada de material refratário, e aguarda a solidificação do metal. Com a solidificação do metal dissolve-se a massa refrataria em um banho de água, cortando os as peças criadas na árvore, por fim essas peças seguem para o processo de acabamento.

A etapa da modelagem é de fundamental importância visto que todo o processo reflete o que é feito no molde. Nessa etapa as técnicas artesanais são essenciais, e dependem diretamente do ourives seu conhecimento e sua experiência aplicando-as.

\section{A PRODUÇÃO JOALHEIRA ATRAVÉS DA MANUFATURA ADITIVA}

O uso da impressão 3D nesse setor se deu inicialmente na etapa de prototipagem, eliminando o trabalho manual na construção do modelo. Com o avanço dessa tecnologia foi então possível utiliza-la em outras etapas como a impressão dos moldes de borracha e mais tarde até mesmo a árvore de fundição. Segundo Adler e Fryé (2006) com o uso da impressão 3D para a prototipagem rápida no setor joalheiro, novos paradigmas para os projetos e fabricação de joias surgiram.

$\mathrm{O}$ uso de tecnologia, e ferramentas de modelagem e manufatura já foram introduzidas no contexto da joalheria. Segundo Benz (2009) conforme os custos do maquinário da impressão 3D foi diminuindo, o uso dessa tecnologia para a construção do modelo da joia foi ganhando espaço. Além dos custos, a precisão das máquinas de impressão 3D com seu desenvolvimento técnico foi fundamental para que essa tecnologia fosse utilizada no segmento. A capacidade de construir formas complexas e de tamanhos variados passa a atender as demandas especificas por joias com detalhes minúsculos. Assim com o uso da manufatura aditiva as superfícies e espessuras dos modelos passam a ser mais uniformes o que melhora o fluxo de fundição, gerando peças de maior qualidade.

A modelagem artesanal varia com os diferentes modelos e detalhes das joias, com isso o ourives gasta mais tempo com peças mais complexas e muitas vezes não consegue reproduzir fielmente os designs dessas peças. A impressão 3D reproduz exatamente aquilo que está no design e o dispêndio de material é menor com o uso dessa tecnologia. Com o avanço da tecnologia, e o progresso das formas de impressão, em diferentes tipos de materiais abre espaço para utilizar a impressão 3D além dos modelos para utilização por fundição de cera perdida, imprimir em metais passa a ser possível e assim pode eliminar-se quase todo o processo tradicional. As partes de acabamento ainda dependerão dos processos tradicionais e do ourives. 


\section{ESTUDO DE CASO: AS DIFERENÇAS DE CUSTO DE UMA MESMA JOIA PRODUZIDA ARTESANALMENTE OU PRODU- ZIDA POR MANUFATURA ADITIVA}

O design do anel foi feito na loja do artesão, pelo próprio, usando apenas caneta e papel (Figura 2). O nome dado ao design foi Ammolite Ring, e como pode ser visto na imagem abaixo a circunferência do anel será de $54 \mathrm{~mm}$, terá pequenos diamantes e uma pedra maior no centro. Será côncavo por baixo, para ter seu peso diminuído, e estima-se que o anel pesará quando acabado de 6 a 7 gramas. Na lateral do anel foram adicionados pequenos detalhes.

Figura 2 - Foto do design Ammolite ring, feito pelo artesão, Doug Andrews

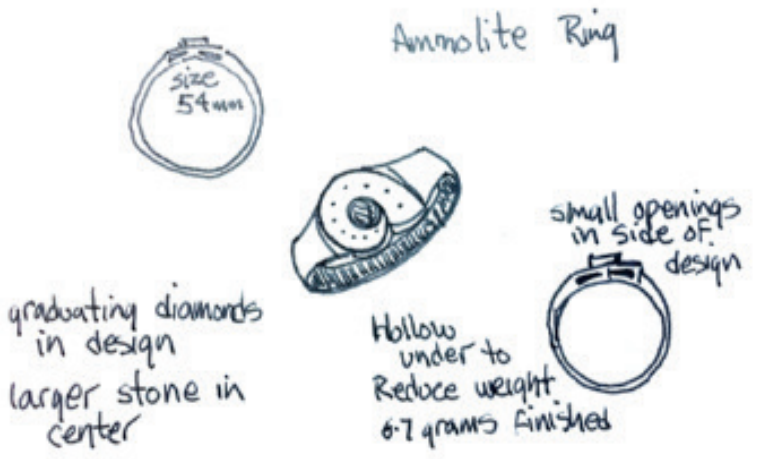

Fonte: Arquivo dos autores.

Como o anel é uma peça única, o artesão modelou a peça em cera, que custa CAD 18,90 e que tem como característica ser flexível e ter o ponto de fusão mais baixo do que as outras ceras usadas para modelagem de joias (Figura 3). Com o modelo foi feito um molde em gesso e então feito o processo de fundição por cera perdida, já descrito nesse artigo.

Figura 3 - Foto da cera utilizada, o modelo do anel em cera e anel após o procedimento de cera perdida



Fonte: Arquivo dos autores. 
Para o design foram gastas uma visita com o cliente de 30 minutos, 1,3 horas para o desenho, especificações, correções de alguns detalhes pós validação com o cliente e outro encontro de 30min para validação do modelo com o cliente. Para modelar a joia na cera foram gastas 2.2 horas. O custo da hora cobrada pelo artesão é de CAD 30,00 (dólares canadenses). Fazer o modelo em gesso e executar o método por cera perdida teve um custo de CAD 125,00 além de mais uma hora de trabalho aproximadamente. $\mathrm{O}$ valor do ouro branco utilizado no anel é de CAD 39,77 por grama. Foram utilizados 7,9 gramas de ouro branco o que totalizou em CAD 314,19 (Figura 4).

Para a confecção do anel até o ponto do acabamento foram gastos um total de CAD 165,00 de mão de obra, CAD 458,09 em materiais para modelagem em cera, gesso e o ouro branco utilizado. O que totaliza até esta etapa do processo, CAD 623,09.

Figura 4 - Foto do anel após o processo de fundição por cera perdida.
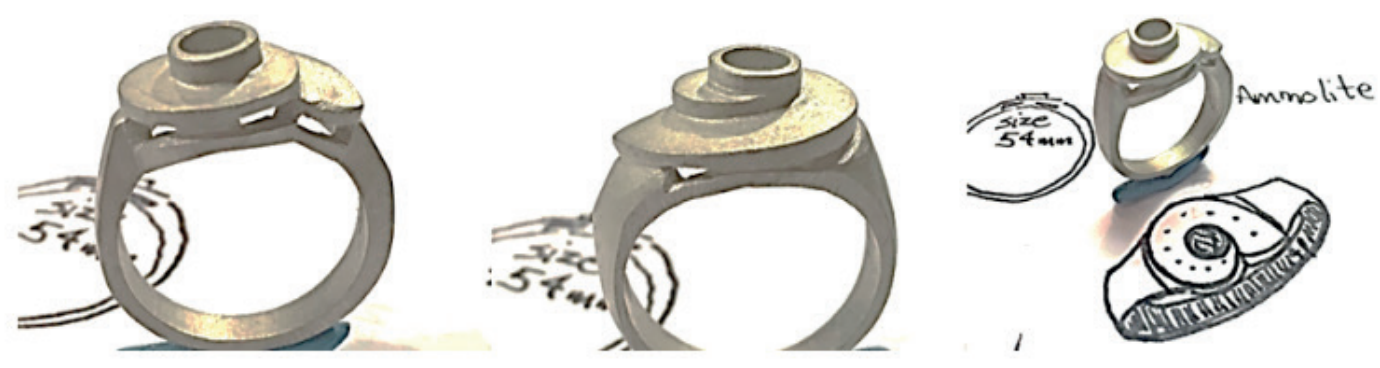

Fonte: Arquivo dos autores.

Após todos os acabamentos o anel pesará aproximadamente 6,25 gramas, isso significa que 1,65 gramas do ouro branco é desperdiçado nesse processo o que corresponde a CAD 65,62.

Para a confecção do anel por manufatura aditiva vamos considerar o tempo de design o mesmo do artesão, uma vez que foi ele quem criou o modelo. E, para fins de comparação, o custo do tempo gasto em modelagem no software serão CAD 20,75 por hora, já que o custo médio da hora para execução desse trabalho no Brasil é de cerca de $\mathrm{R} \$ 60,00$.

A modelagem em software foi feita pelos autores deste trabalho, utilizando o Autodesk Inventor ${ }^{\circledR}$, um software CAD 3D aplicável em desenvolvimento de produtos. Para essa modelagem foram gastas 2 horas. $\mathrm{O}$ arquivo contendo a matemática foi convertido em formato stl, que é o utilizado pela plataforma Shapeways para orçar a impressão de peças pelo site. Ao fazer o upload do arquivo na plataforma (Figura 5) e especificar o material que o anel deve ser impresso, ouro branco 14 quilates, as especificações de tamanho e quantidade de ouro, temos o valor orçado pelo site de CAD 412,77. Esse valor é o custo do anel já com o acabamento. Adicionando os custos de mão de obra nesse caso de chega-se a um total de CAD 506,99, conforme demonstrado na Figura 6, a seguir. 
Figura 5 - Modelo 3D do anel no site Shapeways após upload do arquivo.
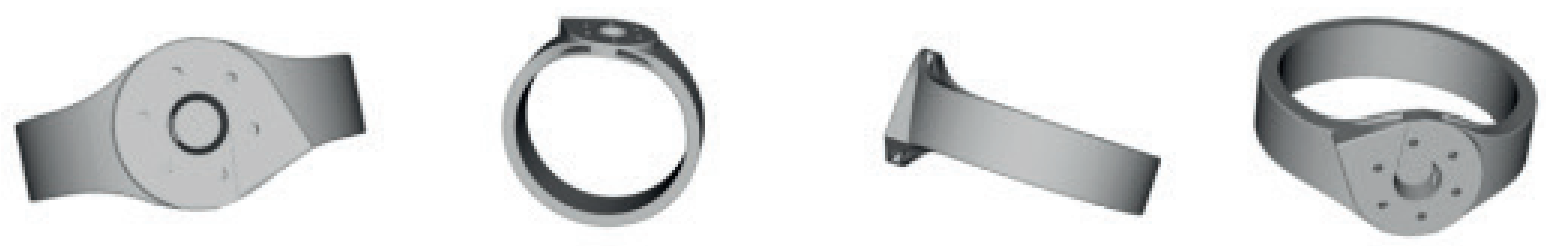

Fonte: https://www.shapeways.com/model/3dtools/7585855/1/97.

Figura 6 - Comparativo de custos do processo artesanal com a peça impressa pela plataforma

\begin{tabular}{|c|c|c|c|c|c|}
\hline \multicolumn{3}{|c|}{ Joalheria Artesanal } & \multicolumn{3}{|c|}{ Site Shapeways } \\
\hline Design & $1.3 \mathrm{~h}$ & CAD 39,00 & Design & $1.3 \mathrm{~h}$ & CAD 39,00 \\
\hline Visitas com cliente & $1 \mathrm{~h}$ & CAD 60,00 & $\begin{array}{l}\text { Modelagem em } \\
\text { software CAD }\end{array}$ & $2 \mathrm{~h}$ & CAD 41,50 \\
\hline Cera para modelagem & - & CAD 18,90 & - & - & \\
\hline Tempo de modelagem em cera & $2.2 \mathrm{~h}$ & CAD 66,00 & - & - & \\
\hline $\begin{array}{l}\text { Gesso e demais matérias para o } \\
\text { processo de cera perdida }\end{array}$ & - & CAD 125,00 & $\begin{array}{l}\text { Orçamento na } \\
\text { plataforma Shapeways, } \\
\text { ouro branco } 14 \mathrm{k}\end{array}$ & $7,9 \mathrm{~g}$ & $\begin{array}{c}\text { CAD } \\
412,77\end{array}$ \\
\hline tempo processo cera perdida & 1 & CAD 30 & - & - & - \\
\hline Ouro Branco $14 \mathrm{k}$ & $7,9 \mathrm{~g}$ & CAD 314,19 & - & - & - \\
\hline TOTAL & \multicolumn{2}{|c|}{ CAD 623,09} & TOTAL & \multicolumn{2}{|c|}{ CAD 506,99} \\
\hline DIFERENÇA & \multicolumn{3}{|c|}{ CAD 116,10} & \multicolumn{2}{|c|}{$18,63 \%$} \\
\hline
\end{tabular}

Fonte: Elaboração dos autores.

O presente trabalho foi realizado com apoio da Coordenação de Aperfeiçoamento de Pessoal de Nível Superior - Brasil (CAPES) - Código de financiamento 001.

O site explica que os modelos em ouro são impressos em 3D usando um processo de cinco etapas. Primeiro, o modelo é impresso em cera usando uma impressora 3D especializada de alta resolução. É então colocado em um recipiente onde o gesso líquido é derramado em torno dele. Quando o gesso é colocado, a cera é derretida em um forno e o gesso restante se torna o molde. O ouro derretido é vertido então neste molde, onde irá se solidificar. O gesso então é quebrado, revelando seu novo produto. $\mathrm{O}$ produto passa por uma limpeza e polimento à mão, processo que remove um pouco de material na superfície, de modo que o volume exato pode ser um pouco menor do que o do modelo digital.

\section{CONCLUSÕES}

O uso da tecnologia 3D para a impressão de peças será cada vez mais comum e viável com o avanço dessa tecnologia e redução nos preços de equipamentos e materiais destinados a esse uso. Como 
as tecnologias presentes na manufatura aditiva trabalham por sistemas automatizados de fabricação, a utilização dessas tecnologias acaba por gerar um dispêndio de tempo menor pelos ourives nas atividades de modelagem além de aumentar a confiabilidade e qualidade nos processos de produção em massa, a impressão 3D possibilita a reprodução das peças com maior precisão e qualidade pois o modelo que será impresso será exatamente igual ao modelo digital, já os modelos feitos artesanalmente sofrem variáveis que podem alterar o design e afetar a qualidade do molde por não serem tão precisos e dependerem exclusivamente das técnicas e experiência de quem faz o modelo. A utilização dessa tecnologia já é realidade no setor joalheiro e vem quebrando paradigmas para outros setores industriais. Com esse avanço na manufatura aditiva poderemos ter em breve máquinas que imprimirão diretamente no material do produto final, como o ouro branco no caso do anel estudado, evitando a perda de materiais. A perda dos 1,65 gramas de ouro branco no acabamento poderá ser diminuída ao imprimir a peça diretamente do ouro. Além disso, a manufatura aditiva se mostrou mais barata na fabricação do anel, abordado no estudo de caso, mesmo utilizando essa tecnologia apenas para o molde, a diferença de custo foi de quase $19 \%$.

Apesar dessa tecnologia possibilitar que pessoas com menos expertises em joias e ourivesaria tenha condição de fabricar uma joia ela não dispensa do profissional qualificado como o ourives. Os detalhes de acabamento e cravação ainda são feitos de forma artesanal e precisa-se ter as técnicas e os conhecimentos para executar essa parte do trabalho. Além disso, podemos notar a expressividade do desenho do artífice e comparar o nível de detalhes em relação à modelagem computacional desenvolvida para o comparativo, onde notamos a "dureza" do software e suas limitações no desenvolvimento de superfícies e formas orgânicas e complexas. Sabemos que existem softwares específicos que permitem modelagens orgânicas complexas e até mesmo mais instigantes que as possibilidades desenvolvidas pela manufatura tradicional. Porém, devemos realçar que o valor das peças produzidas pela joalheria artesanal tradicional também reside em seu caráter individual empregado na produção de peças únicas.

Portanto, acreditamos que o desenvolvimento e uso dessa tecnologia não substituirá os profissionais especializados na área, e sim deixará com que esses profissionais se concentrem nas etapas que geram mais valor e garantem a entrega do produto da forma que o cliente deseja e de forma mais rápida e com um nível de qualidade melhor.

Essa inserção da manufatura aditiva para a fabricação direta na joalheria gradativamente passa a ser economicamente viável. Já existem impressoras desenvolvidas para produzir com metais preciosos com principal foco nesse segmento. Segundo Snyder (2014) as tecnologias que estavam disponíveis para outros segmentos foram adaptadas para as demandas especificas da joalheria. Mas, mesmo com esse avanço e com a adoção da manufatura aditiva pela indústria joalheira, segundo Monteiro, Krucken e Lana (2014), o uso dessa tecnologia ainda está concentrado na fabricação da peça modelo já que a produção por cera perdida é mais viável economicamente falando em uma produção em es- 
cala. $\mathrm{O}$ fato de ainda não existirem tantos fornecedores de matéria prima para impressão 3D de joias e os fornecedores de maquinários criarem uma barreira onde suas máquinas sejam incapazes de utilizar materiais de outros fornecedores.

\section{Referências}

ABREU, S. Impressão 3D baixo custo versus impressão em equipamentos de elevado custo. 102f. 2015. Dissertação (Mestrado Integrado em Engenharia Mecânica) - Faculdade de Engenharia, Universidade do Porto, Porto, Protugal, 2015.

ADLER, S.; FRYÉ, T. The revolution of CAD/CAM in the casting of fine jewelry. Rapid Prototyping and Manufacturing 2006. Society of Manufacturing Engineers, p. 24, 2006.

CARVALHO, L.; OLIVEIRA, L.; PINTO, M.; JÚNIOR, M.; Sistemas de produção na joalheira: do projeto à entrega do produto final. Dossiê Técnico, Serviço brasileiro de respostas técnicas, 2012.

COPRUCHINSKI, L. A Arte de Desenhar joias. Curitiba: Léia Copruchinski, 2011.

GOLA, E. A joia: História e Design. São Paulo: SENAC, 2008.

GREEnBERG, A. These 3-D Printed Skeleton Keys Can Pick High-Security Locks in Seconds. 2014. Disponível em: http://www.wired.com/2014/08/ 3d-printed-bump-keys/?mbid=social_ twitter. Acesso em: 27.mar. 2018.

HE ART JOIA. Fundição por cera perdida ou microfusão. 2012. Disponível em: http://heartjoia.com/4485-fundicao-cera-perdida-microfundicao-ouro-prata. Acesso em 15.mai. 2018.

HOHKRAUT, U. Rapid Prototyping and Jewelry Design. In: INTERNATIONAL ASSOCIATION FOR AUTOMATION AND MANUFACTURING. 21 st. 2010. Anais... DAAAM, Zadar: Danube Adria (DAAAM). 2010. p. 2.

KARASINKI, V. Como funciona uma impressão 3D? 2013. Disponível em: https://www.tecmundo.com.br/impressora-3d/38826-como-funciona-uma-impressora-3d-ilustracao-.htm. Acesso em: 15.Mar. 2018 
KLIAUGA, A. M.; FERRANTE, M. Metalurgia básica para ourives e designers do metal à joia. Editora Blucher, 2009. 337 p.

LIPSON, H..; KURMAN, M. Fabricated: The New World of 3D Printing. Indianápolis: John Wiley and Sons, Inc., 2013.

MONTEIRO, M. T. F.; KRUCKEN, L.; LANA, S. Potencialidades da impressão 3D sob a perspectiva do design: uma análise do setor de joalheria em Belo Horizonte. In: CONGRESSO BRASILEIRO DE PESQUISA E DESENVOLVIMENTO EM DESIGN. 11. 2014. Anais... Gramado: UFGRS. 2014. p. 11.

PAIM, R. et al. Gestão de processos: pensar, agir e aprender. Porto Alegre: Bookman, 2009. 327 p.

PIPES, A. Desenho para designers. São Paulo: Blucher, 2010.

SALGADO, E. G.; MELLO, C. H. P.; SILVA, C. E. S. da; OLVEIRA, E. S.; ALMEIDA, D. A. Análise da aplicação do mapeamento do fluxo de valor na identificação de desperdícios do processo de desenvolvimento de produtos. Revista Gestão da Produção, v.16, n.3, p.344-356, 2009.

SIAS, F. R. Lost-Wax Casting: old, new, and inexpensive methods. Pendleton: Woodsmere Press, 2005.

SLACK, N.; CHAMBERS, S.; JOHNSTON, R. Administração de Produção. São Paulo: Atlas, 2009.

SNYDER, T. W. The Ganoksin Project. Additive Manufacturing Beams Down to the Jewelry Scene Growing Up, 2014. Disponivel em: http:/www.ganoksin.com/borisat/nenam/jewelry-additive-manufacturing-system.htm. Acesso em: 17 maio 2018.

TAKAGAKI, L. K. Tecnologia de Impressão 3D. Revista Inovação Tecnológica, v. 2, n. 2, p. $28-40,2012$. 